\title{
Effect of Transcranial Direct Current Stimulation on Movement Variability in Repetitive - Simple Tapping Task
}

\author{
Yong Hyun Kwon', Jeong Sun Cho ${ }^{2}$ \\ ${ }^{1}$ Department of Physical Therapy, Yeungnam University College, Daegu; ${ }^{2}$ Science Culture Research Center, Pohang University of Science and \\ Technology, Pohang, Korea
}

Purpose: Accuracy and variability of movement in daily life require synchronization of muscular activities through a specific chronological order of motor performance, which is controlled by higher neural substrates and/or lower motor centers. We attempted to investigate whether transcranial direct current stimulation (tDCS) over primary sensorimotor areas (SM1) could influence movement variability in healthy subjects, using a tapping task.

Methods: Twenty six right-handed healthy subjects with no neurological or psychiatric disorders participated in this study. They were randomly and equally assigned to the real tDCS group or sham control group. Direct current with intensity of $1 \mathrm{~mA}$ was delivered over their right SM1 for 15 minutes. For estimation of movement variability before and after tDCS, tapping task was measured, and variability was calculated as standard deviation of the inter-tap interval (SD-ITI).

Results: At the baseline test, there was no significant difference in SD-ITI between the two groups. In two-way ANOVA with repeated measurement no significant differences were found in a large main effect of group and interaction effect between two main factors (i.e., group factor and time factor (pre-post test)). However, significant findings were observed in a large main effect of the pre-post test.

Conclusion: Our findings showed that the anodal tDCS over SM1 for 15 minutes with intensity of 1 mA could enhance consistency of motor execution in a repetitive-simple tapping task. We suggest that tDCS has potential as an adjuvant brain facilitator for improving rhythm and consistency of movement in healthy individuals.

Keywords: Transcranial direct current stimulation, Movement variability, Tapping task, Primary sensorimotor cortex

\section{서 론}

율동적인 움직임(Rhythmic movement)과 움직임의 타이밍(movement timing)은 일상생활동작이나춤, 음악, 스포츠 등과 같은 행위를 하는 동안 쉽게 관찰될 수 있고, 인체의 움직임을 실행(execution)하고 통합 (organization)하는 근본적인 요소 중의 하나이다.1,2 이러한 율동과 타 이밍은 연속적 순서로 수행되는 여러 동작들을 성공적으로 실행하 기 위한 움직임의 통합이라 볼 수 있다. 인체의 움직임에서 특정 동작 의 반복적 연속 과정인 보행 및 탭핑 (tapping)과 같이 동작은 협응 (coordination) 능력이 필요한데, 이는 상위 및 하위 신경계의 상호작 용이 필요한 리듬을 일컫는다. ${ }^{3-5}$ 리듬은 움직임의 타이밍을 요구하

Received January 13, 2015 Received February 9, 2015

Accepted February 11, 2015

Corresponding author Jeong Sun Cho

E-mail cjs9691@postech.ac.kr
는 대부분의 일상적인 활동들을 위해 필수적인 요소이며, 반복적인 리듬의 속도를 빠르게 또는 느리게 하거나 그 속도를 유지하는 것이 필요하다. 예를 들면, 악기의 연주, 춤, 박수 등과 같은 동작들은 시간 적 요소가 필요한 외적인 자극과 함께 잘 조절된 협응의 결과라 볼 수 있다.

리듬과 타이밍에 대한 움직임의 특징적 요소를 판별하는 가장 효 과적인 도구가 손가락 타판 과제(finger tapping task)이다. ${ }^{6}$ 타판 과제 는 외부의 청각적 자극과 함께 수행될 수 있는데, 그 첫 번째 단계는 대상자가 지속적인 자극 간 간격(constant inter-stimulus interval)에 의 해 구분되는 일련의 청각적 자극에 손가락을 동기화(synchronization)하기 위해 노력하는 동기화 단계를 거치고, 그 다음으로는 대상

Copylight @ 2015 The Korean Society of Physical Therapy

This is an Open Access article distribute under the terms of the Creative Commons Attribution Non-commercial License (Http:// creativecommons.org/license/by-nc/3.o.) which permits unrestricted non-commercial use, distribution, and reproduction in any medium, provided the original work is properly cited.

- This research was supported by Basic Science Research Program through the National Research Foundation of Korea (NRF) funded by the Ministry of Science, ICT \& Future Planning (2012R1A1B4003477). 
자가 청각적 자극이 제시되지 않더라도 그전에 수행하여 왔던 속도 로 일관되게 타판하려고 노력하는 지속화(continuation) 단계로 진행 하게 된다. ${ }^{6}$ 이러한 움직임의 동기화와 지속화가 필요한 과제에서 운 동 반응의 정확성(accuracy)과 변이성(variability)을 측정하는 것은 운 동과학을 연구하는 분야에서 매우 관심 있는 영역이다. 정확성은 타 판 행위의 결과가 목표 지점을 얼마나 정확하게 수행하였는가를 말 하고, 변이성은 타판 행위의 결과가 얼마나 일관성 있게 수행하였는 지를 의미한다. 타판 과제에서 정확성과 변이성의 측정은 심인성 장 애 또는 가병(malingering)을 판별할 수 있는 신경심리학적 평가도구 로도 활용되고 있다.7-9

최근 생체의 뇌신경 세포에 비침습적인 방법으로 $1-2 \mathrm{~mA}$ 의 미세전 류를 적용하여 운동, 감각, 인지 등의 다양한 뇌기능을 조절할 수 있 는 기법으로 경두개 직류전기자극(transcranial direct current stimulation)이 새롭게 재도입되었다.1011 경두개 직류전기자극은 극성에 따라 서로 다른 효과를 나타내는데, 양극에서는 전극 아래에 있는 뇌신경 세포들의 기능을 촉진하는 역할을 하고 음극에서는 뇌세포의 기능 을 억제하는 역할을 한다.12-14 이러한 경두개 직류전기자극의 극성 효 과를 이용하여 인체의 운동 및 감각기능을 촉진하는 도구로써 현재 까지 활발한 연구가 진행되고 있다. 경두개 직류전기자극을 이용한 많은 연구에서 자극을 가하는 동안이나 자극 후 일정한 시간 내에서 다양한 운동 기능의 촉진을 제시하고 있다. 현재 경두개 직류전기자 극이 운동기능의 향상을 입증하기 위한 연구에서 제시한 바에 의하 면, 자극 후 근력의 강화, 피로에 대한 저항성 증가, 시지각 운동과제 에서의 협응력 향상, 운동 반응 속도의 증가를 비롯하여 암묵적 및 외현적 운동학습을 촉진하는 것으로 알려져 있다.15-20 그러나 인체 움 직임의 필수적인 리듬과 타이밍의 속성을 가진 운동 과제를 통해 움 직임의 변이성에 경두개 직류전기자극이 어떠한 영향을 미치는지에 관한 연구는 드물다. 따라서 본 연구에서는 경두개 직류전기자극이 움직임의 리듬과 타이밍의 속성을 가진 반복적 타판 과제에서 움직 임의 변이성에 어떠한 영향을 미치는지를 알아보고자 하였다.

\section{연구방법}

\section{1. 연구 대상자}

본 연구에 참여한 대상자는 Edinburg Handedness Inventory 검사에서 오른손이 우성으로 판정된 20대 성인 26명을 대상으로 실시하였다. 모든 대상자는 최근 2 년 동안 오른쪽 상지에 근골력계 질환을 호소 하지 않았고 신경학적 질환이 없는 자로 선정하였다. 실험에 참가하 기 전 연구의 목적과 방법에 대해 충분한 설명을 듣고 자발적 동의를 한 후에 실험에 참가하였다. 실험에 참가한 대상자들은 무작위 선정 방식으로 경두개 직류전기자극군(tDCS group)과 위약 자극군(sham
tDCS group)으로 배정되었다. 본 연구는 지역의 기관생명윤리심의위 원회(institutional review board)에서 사회적 행동과학연구(social behavioral research)의 승인을 받은 후 실시되었다.

\section{2. 실험 절차}

1) 경두개 직류전기자극(transcranial direct current stimulation, tDCS) 모든 대상자는 등받이가 있는 의자에 편안하게 앉아서 경두개 직류 전기자극을 받았다. 경두개 직류전기 자극기는 미국의 IOMED사에 서 제작된 Phoresor II Auto (Model PM 850)을 사용하여 $5 \times 7 \mathrm{~cm}$ (35 $\mathrm{cm}^{2}$ ) 크기의 고무로 된 두 개의 전극에 함염물(saline)에 적셔진 스폰 지를 사용하여 1 밀리 암페어의 전류가 15 분 동안 통전되었다. 통전 된 총 전류의 양은 생체 조직을 손상하지 않는다고 입증된 $0.029 \mathrm{~mA} /$ $\mathrm{cm}^{2}$ 의 전류가 통전되었다. ${ }^{21}$ 전극의 배치는 뇌파 측정의 $10 / 20$ 체계의 국제적 기준(10/20 international electroencephalographic system)에 따 라 양전극(anodal electrode)을 우측 뇌반구의 C4 위에 위치하였다. C4 부위는 일차운동감각영역에 해당하는 부위로써, 손의 운동 기능을 관할하는 곳으로 알려져 있다.22,23 음전극(cathodal electrode)는 우측 뇌반구의 안와상 영역(supraorbital area)에 부착하였다. 모든 대상자 는 전류가 통전되는 기간 동안 아무런 불평을 호소하지 않고 전 구간 을 수행 완료하였고, 일부 대상자들은 전극이 배치된 부위에 가벼운 간지러움을 느꼈다. 위약 자극군에서는 동일한 자극기를 사용하여 전류를 통전하지 않았지만, 대상자는 전류가 통전되는 것으로 인식 하도록 하였다.

\section{2) 타판 과제}

타판 과제는 여덟 개의 반응 버튼을 가진 반응패드(RB-830, Cedrus, USA)와 반응 과제를 구성하기 위한 자극 제공 프로그램(SuperLab Pro version 4.0, Cedrus, USA)이 설치된 개인용 컴퓨터를 사용하여 통 전 전후의 측정과제로 사용되었다. 대상자는 주관절이 $90^{\circ}$ 가 되도록 높이 조절이 가능한 탁자 앞에 편안한 자세로 앉아 눈높이에 있는 컴 퓨터 모니터를 응시하고, "준비" 신호가 모니터에 표시된 후 "시작" 신 호가 제시되면 대상자는 왼쪽 두 번째 손가락의 중수지절관절 (metacarpophalangeal joint)에서 정해진 버튼을 편안한 속도로 일관성 있게 15 초 동안 타판하도록 하였다(Figure 1). 사전 연습은 1번 실시하였고, 실제 측정은 2 번 실시하여 타판 간 반응시간 간격의 표준편차(standard deviation of inter-tap interval)를 측정하고 평균값을 사용하였다.

\section{3. 통계분석}

대상자의 일반적 특성인 성별에서 두 집단의 분포 비율의 차이를 비 교하기 위해 카이스퀘어검정 ( $\chi^{2}$ test)을 사용하였고 대상자의 나이와 경두개 직류전류의 자극 전 움직임의 변이성에 대한 두 집단 비교를 


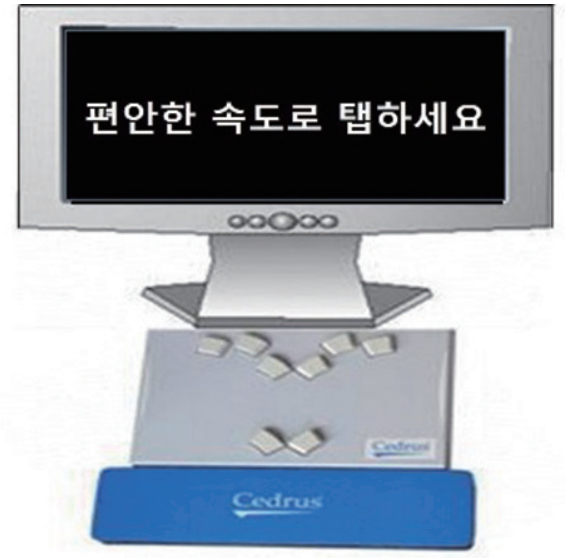

Figure 1. The schema of tapping task.

위해 독립 $\mathrm{t}$ 검정을 사용하였다. 움직임의 변이성에 대한 경두개전류 전기의 효과 입증을 위해 이요인 반복 측정 분산 분석(two-way ANOVA with repeated measurement)을 사용하였고 집단 간 요인 및 훈련 전 후의 반복 요인을 독립 변인으로, 타판 간 반응시간 간격의 표준편차 를 종속변인으로 설정하였다. 두 집단에서 타판 간 반응시간 간격의 표준편차의 변화 차이는 독립 t 검정으로 분석하였다. 모든 통계 처리 는 윈도우용 SPSS 18.0 을 사용하였고 통계적 유의 수준은 $\alpha=0.05$ 로 설정하였다.

\section{결 과}

참여한 모든 대상자는 총 26 명으로 남자가 8 명이었고, 평균 나이는 $21.73 \pm 1.28$ 세이었다. 경두개 직류전기자극군은 총 13 명으로 남자가 4 명이었고, 평균 나이는 $21.92 \pm 0.76$ 이었다. 위약 자극군은 총 13 명으로 남자가 4 명이었고, 평균 나이는 $21.54 \pm 1.66$ 이었다. 두 집단의 남녀 분 포 차이는 통계적으로 유의하지 않았고 $(\mathrm{p}=1.000)$, 나이의 차이도 통 계적으로 유의하지 않았다 $(\mathrm{p}=0.456)$.

경두개 직류전기자극군에서 타판 간 반응시간 간격의 표준편차 는 자극 전 $31.15 \pm 10.40$ 에서 자극 후 $22.19 \pm 7.96$ 으로 변화하였고, 그 변화량은 $8.96 \pm 13.48$ 이었다. 위약 자극군에서 타판 간 반응시간 간격 의 표준편차는 자극 전 $31.79 \pm 15.22$ 에서 자극 후 $28.18 \pm 13.57$ 으로 변 화하였고, 그 변화량은 $3.61 \pm 7.17$ 이었다. 이요인 반복측정분산분석 결과, 집단 간 주 효과 검정은 통계적으로 유의하지 않았고 $\left(\mathrm{F}_{(1,24)}=\right.$ 0.609, $\mathrm{p}=0.443$ ), 사전-사후주 효과 검증에서는 통계적으로 유의한 결 과를 보였으며 $\left(\mathrm{F}_{(1,24)}=8.819, \mathrm{p}=0.007\right)$, 집단 및 사전-사후 상호작용에 서는 통계적으로 유의한 결과를 보이지 않았다 $\left(\mathrm{F}_{(1,24)}=1.597, \mathrm{p}=0.218\right)$ (Table 1).
Table 1. Comparison of Inter-tap interval between the real tDCS group and sham tDCS group

\begin{tabular}{clcc}
\hline & & Real tDCS group & Sham tDCS group \\
\hline Inter-tap interval & Pre test & $31.15 \pm 10.40$ & $31.79 \pm 15.22$ \\
$(\mathrm{~ms})$ & Post test & $22.19 \pm 7.96$ & $28.18 \pm 13.57$ \\
& Change & $8.96 \pm 13.48$ & $3.61 \pm 7.17$ \\
(pre- to post-test) & & \\
Statistical results & Group effect & $\mathrm{F}_{(1,24)}=0.609, \mathrm{p}=0.443$ \\
& Pre-post effect & $\mathrm{F}_{(1,24)}=8.819, \mathrm{p}=0.007$ \\
& $\begin{array}{c}\text { Interaction between } \\
\text { group and pre-post } \\
\end{array}$ & $\mathrm{F}_{(1,24)}=1.597, \mathrm{p}=0.218$ \\
& & \\
\hline
\end{tabular}

고 찰

본 연구는 타판 과제를 통해 경두개 직류전기자극이 반복적이고 율 동적인 움직임의 변이성에 영향을 미칠 수 있는지를 알아보고자 하 였다. 그 결과, 위약 자극군에서는 타판 간 반응시간 간격의 표준편차 인 움직임의 변이성이 $3.61 \mathrm{~ms}$ 만큼 줄었으나, 경두개 직류전기자극 군에서는 자극 전에 비해 자극 후 $8.96 \mathrm{~ms}$ 만큼 움직임의 변이성이 더 많이 줄어든 것을 확인하였다. 위약 자극군에서 움직임의 변이성이 다소 감소한 원인은 타판 과제의 반복으로 인한 습관화와 학습에 의 한 것으로 생각된다. 위약 자극군에서 학습 효과로 인한 변이성의 감 소로 인해 이요인 반복측정분산분석에서 집단 간주 효과 검정 및 상 호작용에서 통계적 유의성이 나타나지 않았고, 사전-사후 주 효과 검 정에서만 통계적 유의성을 보였다. 움직임의 변이성의 감소는 대상자 가 타판 과제를 수행할 때, 일관된 속도로 율동적인 움직임을 수행했 다는 것을 의미하며, 타판 과제에 관여하는 근육군들의 협응과 근수 축 시너지가 보다 향상된 결과라 볼 수 있다. 따라서 15 분간 일차운동 감각영역에 적용된 경두개 직류전기자극은 반복적이고 율동적인 움 직임(repetitive rhythmic movement)을 일관성 있게 수행할 수 있는 능 력을 향상시켰다고 볼수 있다.

연속적 운동 과제(sequential task)의 수행에서 하부 동작들의 간격 간 변이성(interval-to-interval variability)은 움직임의 타이밍에 핵심적 인 특성이기 때문에, 인체 동작의 이론 체계를 설명하는 데 결정적인 요소로 인식되고 있다. ${ }^{24}$ 또한 움직임의 타이밍이 필요로 하는 과제 는 학습의 필수적인 요소이며, 동기화가 필요로 하는 과제에서는 음 악 전문가가 비전문가에 비해 움직임의 변이성이 더 낮다는 것이 입 증되었다. ${ }^{25}$ 타판 과제는 상지의 섬세한 운동 기술(fine motor skill)을 객관적으로 평가할 수 있으며, 움직임의 장애(movement disorder), 심 인성 상태(psychogenic condition), 가병(malingering) 등을 포함한 다 양한 신경학적 질병을 파악할 수 있는 도구이다. 82,26 Arnold 등 26 은 가병을 호소하는 것으로 의심되는 사람과 치매, 뇌손상, 우울증과 같 은 다양한 신경학적 질환을 가진 사람들에게서 타판 과제의 변이성 
을 비교 분석한 결과, 신경학적 손상에도 불구하고 가병을 가진 사람 에게서 더 많은 변이성이 발견되었다고 보고하였다. 따라서 타판 과 제의 변이성의 감소는 인체 움직임에서 근수축 활동의 서니지 작용 과 협응 능력의 향상으로 보다 섬세하고 부드럽고 일관된 동작의 수 행의 결과라 볼수 있다.

본 연구에서 제시한 바와 같이, 경두개 직류전기자극에 의한 타판 과제의 변이성 감소로 기인하는 운동 기능 향상의 결과는 운동 기능 의 효과를 입증한 많은 선행 연구들과 유사한 결과를 제시하고 있

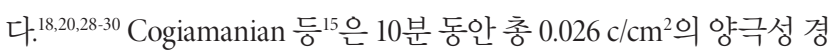
두개 직류전기자극을 정상인의 우측 뇌반구 일차운동영역을 자극 한 후, 왼쪽 팔꿈치 굴곡 근육의 최대하 등척성 수축에 대한 지구력 을 측정하였는데, 그 결과 위약 자극군에 비해 근피로에 대한 저항력 이 강화되었다고 보고하였다. 이러한 결과는 경두개 직류전기자극이 운동 기능의 가장 근본적인 요소인 근수축력과 지구력에 직접적이 고 가시적 효과를 나타낼 수 있는 것으로 생각된다. 또한 기본적인 운 동 기능의 향상을 넘어 시열반응과제에서 운동자극에 대한 반응시 간이 단축된다거나, 시지각과제에 운동 수행 능력의 정확도가 향상 됨이 보고되고 있다.31,32 이와 같은 운동 기능 향상에 대한 증거와 함 께, 양극성 직류전기의 자극이 운동 학습의 효율성을 증대시키는 등 운동 수행에 관련된 다양한 운동 능력 향상의 행동학적이고 정량적 자료를 제시하고 있을 뿐 아니라, 이에 대한 신경생리학적 기전을 증 명하는 뇌지도화 연구에서 그 효과가 입증되고 있다. ${ }^{33-35}$

최근 경두개 직류전기자극은 Nitsche와 Pauluso ${ }^{10}$ 에 의해 1990년대 에 새롭게 부각되기 시작하여 1-2 mA의 미세전류를 생체의 두피에 비침습적인 방법으로 뇌를 자극하는 기법이다." 인체의 움직임은 뇌 의 중앙 집중적 제어와 말초신경 및 근육의 복합적 작용으로 유발되 고 있으며, 아직까지도 움직임의 양상과 병리적 기전을 명료하게 설명 하기 어렵다. 또한 인체의 움직임의 능력을 향상시키거나 기능의 손 상 후에 회복을 위한 다양한 노력이 시도되고 있다. 따라서 생체에서 뇌를 비침습적으로 안전한 방법으로 자극하여 운동 능력을 조율할 수 있다는 것은 신경과학의 분야에서 매우 흥미 있는 주제이다. 본 연 구에서는 경두개 직류전기자극이 운동의 변이성을 감소하여 협응력 을 증가시킨다는 것을 확인하였다. 이러한 결과는 뇌신경생리학적 측 면에서 일차운동감각영역이 운동의 변이성에 관여할 수 있다는 것 을 암시하고, 운동의 협응 능력이 필요한 사람이나 뇌손상으로 그 기 능의 회복이 필요한 환자에게 안전한 방법으로 적용할 수 있을 것으 로 생각된다. 본 연구의 제한점은 타판 과제의 특이성이 뇌반구 편측 화(hemispheric lateralization)에 관여하고 있다는 사실을 고려하지 않 고, 단지 운동 변이성에 영향을 미칠 수 있는지를 확인하였다. 향후 뇌반구 편측화를 고려하여 경두개 직류전기자극의 운동 변이성에 관한 연구가 진행되어야 할 것으로 제안한다.

\section{ACKNOWLEDGEMENTS}

This research was supported by Basic Science Research Program through the National Research Foundation of Korea (NRF) funded by the Ministry of Science, ICT \& Future Planning (2012R1A1B4003477).

\section{REFERENCES}

1. Cousins MS, Corrow C, Finn M, et al. Temporal measures of human finger tapping: Effects of age. Pharmacol Biochem Behav. 1998;59(2):445-9.

2. Iannarilli F, Vannozzi G, Iosa M, et al. Effects of task complexity on rhythmic reproduction performance in adults. Hum Mov Sci. 2013;32 (1): 203-13.

3. Chen Y, Ding M, Kelso JA. Origins of timing errors in human sensorimotor coordination. J Mot Behav. 2001;33(1):3-8.

4. Hausdorff JM, Yogev G, Springer S, et al. Walking is more like catching than tapping: Gait in the elderly as a complex cognitive task. Exp Brain Res. 2005;164(4):541-8.

5. Jjspeert AJ. Central pattern generators for locomotion control in animals and robots: A review. Neural Netw. 2008;21(4):642-53.

6. Claassen DO, Jones CR, Yu M, et al. Deciphering the impact of cerebellar and basal ganglia dysfunction in accuracy and variability of motor timing. Neuropsychologia. 2013;51(2):267-74.

7. Demakis GJ. Serial malingering on verbal and nonverbal fluency and memory measures: An analog investigation. Arch Clin Neuropsychol. 1999;14(4):401-10.

8. Kalogjera-Sackellares D, Sackellares JC. Intellectual and neuropsychological features of patients with psychogenic pseudoseizures. Psychiatry Res. 1999;86(1):73-84.

9. Matheson LN, Bohr PC, Hart DL. Use of maximum voluntary effort grip strength testing to identify symptom magnification syndrome in persons with low back pain. J Back Musculoskelet Rehabil. 1998;10(3): 125-35.

10. Nitsche MA, Paulus W. Transcranial direct current stimulation--update 2011. Restor Neurol Neurosci. 2011;29(6):463-92.

11. Priori A, Berardelli A, Rona S, et al. Polarization of the human motor cortex through the scalp. Neuroreport. 1998;9(10):2257-60.

12. Stagg CJ, Nitsche MA. Physiological basis of transcranial direct current stimulation. Neuroscientist. 2011;17(1):37-53.

13. Rushworth MF, Johansen-Berg H, Gobel SM, et al. The left parietal and premotor cortices: Motor attention and selection. Neuroimage. 2003;20 (Suppl 1):S89-100.

14. Krause V, Weber J, Pollok B. The posterior parietal cortex (ppc) mediates anticipatory motor control. Brain Stimul. 2014

15. Cogiamanian F, Marceglia S, Ardolino G, et al. Improved isometric force endurance after transcranial direct current stimulation over the human motor cortical areas. Eur J Neurosci. 2007;26(1):242-9.

16. Hunter T, Sacco P, Nitsche MA, et al. Modulation of internal model formation during force field-induced motor learning by anodal transcranial direct current stimulation of primary motor cortex. J Physiol. 2009; 587(Pt 12):2949-61.

17. Furubayashi T, Terao Y, Arai N, et al. Short and long duration transcra- 
nial direct current stimulation (tdcs) over the human hand motor area. Exp Brain Res. 2008;185(2):279-86.

18. Butts RJ, Kolar MB, Newman-Norlund RD. Enhanced motor skill acquisition in the non-dominant upper extremity using intermittent theta burst stimulation and transcranial direct current stimulation. Front Hum Neurosci. 2014;8451.

19. Sriraman A, Oishi T, Madhavan S. Timing-dependent priming effects of tdcs on ankle motor skill learning. Brain Res. 2014:158123-9.

20. Foerster A, Rocha S, Wiesiolek C, et al. Site-specific effects of mental practice combined with transcranial direct current stimulation on motor learning. Eur J Neurosci. 2013;37(5):786-94.

21. Nitsche MA, Liebetanz D, Lang N, et al. Safety criteria for transcranial direct current stimulation (tdcs) in humans. Clin Neurophysiol. 2003; 114(11):2220-2; author reply 2-3.

22. Stagg CJ, Jayaram G, Pastor D, et al. Polarity and timing-dependent effects of transcranial direct current stimulation in explicit motor learning. Neuropsychologia. 2011;49(5):800-4.

23. Yousry TA, Schmid UD, Alkadhi H, et al. Localization of the motor hand area to a knob on the precentral gyrus. A new landmark. Brain. 1997; 120 ( Pt 1):141-57.

24. Madison G, Karampela O, Ullen F, et al. Effects of practice on variability in an isochronous serial interval production task: Asymptotical levels of tapping variability after training are similar to those of musicians. Acta Psychol (Amst). 2013;143(1):119-28.

25. Repp BH. Sensorimotor synchronization and perception of timing: Effects of music training and task experience. Hum Mov Sci. 2010;29(2): 200-13.

26. Arnold G, Boone KB, Lu P, et al. Sensitivity and specificity of finger tapping test scores for the detection of suspect effort. Clin Neuropsychol.
2005;19(1):105-20.

27. Rapport LJ, Farchione TJ, Coleman RD, et al. Effects of coaching on malingered motor function profiles. J Clin Exp Neuropsychol. 1998;20(1): 89-97.

28. Dutta A, Chugh S, Banerjee A, et al. Point-of-care-testing of standing posture with wii balance board and microsoft kinect during transcranial direct current stimulation: A feasibility study. NeuroRehabilitation. 2014;34(4):789-98.

29. Weiss PH, Achilles EI, Moos K, et al. Transcranial direct current stimulation (tdcs) of left parietal cortex facilitates gesture processing in healthy subjects. J Neurosci. 2013;33(49):19205-11.

30. Williams JA, Pascual-Leone A, Fregni F. Interhemispheric modulation induced by cortical stimulation and motor training. Phys Ther. 2010; 90(3):398-410.

31. Kim CS, Nam SH, Cho IS. The effects of transcranial direct current stimulation in motor performance of serial reaction time task. J Kor Phys Ther Ther. 2010;22(5):103-8.

32. Kwon YH, Cho JS. Effect of transcranial direct current stimulation on visuomotor coordination task in healthy subjects. J Kor Phys Ther Ther. 2014;26(6):388-92.

33. Kwon YH, Kwon JW, Park SY, et al. Cortical activation by transcranial direct current stimulation and functional electrical stimulation in normal subjects: 2 case studies. J Kor Phys Ther Ther. 2011;23(1):77-82.

34. Jang SH, Ahn SH, Byun WM, et al. The effect of transcranial direct current stimulation on the cortical activation by motor task in the human brain: An fmri study. Neurosci Lett. 2009;460(2):117-20.

35. Kwon YH, Jang SH. The enhanced cortical activation induced by transcranial direct current stimulation during hand movements. Neurosci Lett. 2011;492(2):105-8. 